\title{
Clinical Case: Orbital Hydatic Cyst Revealed by Exophthalmia
}

\section{S Belaaroussi*, K Housni, C Baqadir, L Elmaaloum, B Allali and A Elkettani}

Pediatric Ophthalmology Department, Ibn Rochd Casablanca Hospital, Casablanca, Morocco

*Corresponding Author: S Belaaroussi, Pediatric Ophthalmology Department, Ibn Rochd Casablanca Hospital, Casablanca, Morocco.
Received: November 19, 2020

Published: November 28, 2020

(C) All rights are reserved by $\mathbf{S}$ Belaaroussi., et al.

\begin{abstract}
Orbital hydatidosis is a rare clinical entity that most often affects children and young adults living in rural areas. It is secondary to the orbital development of the taenia Echinococcus granulosus. This aberrant location of hydatidosis is serious because of its consequences, especially of a functional nature, hence the interest of prevention. Morocco is an endemic country where hydatidosis still prevales and is a non-exceptional cause of exophthalmia. We report the case of a 43-year-old patient, in whom an evolutionary unilateral exophthalmia had revealed an orbital hydatic cyst.
\end{abstract}

Keywords: Hydatic Cyst; Exophthalmia; Orbital Location

\section{Introduction}

Hydatic cyst $(\mathrm{KH})$ or heddatidosis is an endemic condition particularly affecting the Mediterranean basin, East Africa, the Middle East, mainly in Mediterranean countries and less widespread in developed countries [1]. It is a parasitic condition caused by Echinococcus granulosus, whose hosts represent sheep and dog [2,3].

In the parasiticcycle, man is only an intermediate host accident. Intermediate hosts become infected byingestion of theparasite's eggs. In the middle host's body, eggs hatch and release tiny embryos with hooks that pass through the lining of the digestive tract and travel through the bloodstream.

The mating is ubiquitous and can thus develop in all regions of the body, mainly at the level of the liver (75\%) lungs (15\%). Intra-orbital location is rare and accounts for 1 to $2 \%$ of all locations [2]. The clinic is dominated by the ophthalmia which represents the master symptom. The amenesis and imagery can lead to diagnosis but the diagnosis of certainty remains anatomopathological. Surgical removal of the cyst is the treatment of choice. We report a case of a single intra-orbital location of a hydatic cyst.

\section{Clinical Observation}

We report the case of a 43-year-old woman, a rural resident with no particular pathological history, admitted to ophthalmological consultation for a painless unilateral exophthalmia of the left eye gradually progressing over the past 2 months.

The interrogation reveals a notion of constant contact with dogs. The clinical examination finds a patient of good general condition who has non-axile exophthalmia; irreducible; painless; non-pulsatile and without inflammatory signs in relation to the left eye with a complete ophthalmoplegia associated with a decrease in visual acuity figured at the fingers from a distance. The background of the eye objectified a grade III papillary edema. The examination of the adelphe eye as well as the rest of the clique examination was uncharted (Figure 1).

The patient received an $\mathrm{x}$-ray examination revealing the presence of a thin-walled liquid formation of $29 \times 20 \times 17 \mathrm{~mm}$ located at the upper-internal angle of the left orbit pushing eyeball out, very much in favor of a parasitic cyst (Figure 2 and 3). 


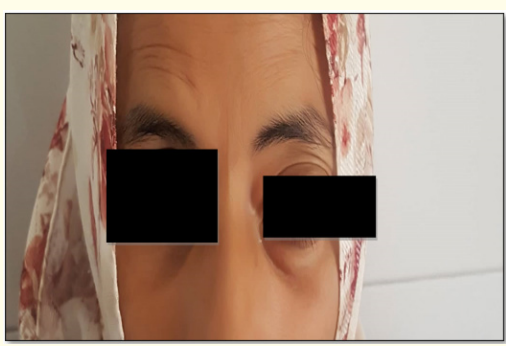

Figure 1: Exophthalmia not axile of the left eye.

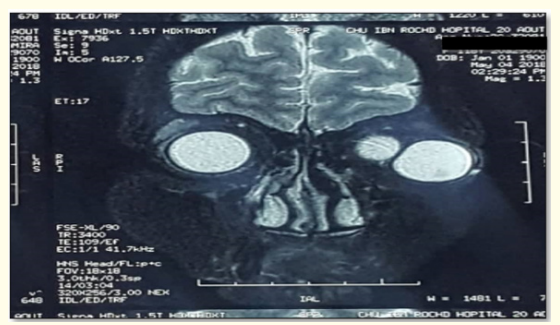

Figure 2: Shot of a head-eared MRI showing left intra conical cystic formation at the upper-internal eye, although limited, in T2 hypersignal.

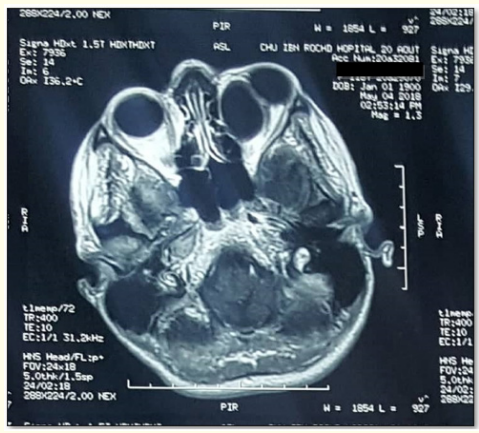

Figure 3: A shot of a cross-section cranio-orbital MRI showing a grossly left intraconasular oval formation at the upper-internal orange, although limited, in hyposignal T1.

Hydatic serology as well as the rest of the routine biological balance were negative. Chest $\mathrm{x}$-rays and abdominal scans have not revealed any other location.

The patient unsumed a surgical exeresis with delivery of the cyst (without breaking it) after an anterior orbitotomy (internal paracanthal) (Figure 4 and 5).

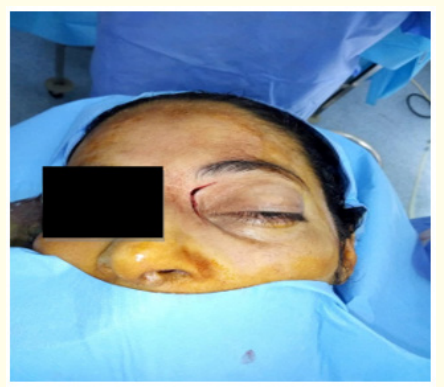

Figure 4: Per-operative image illustrating the site of the first surgical.

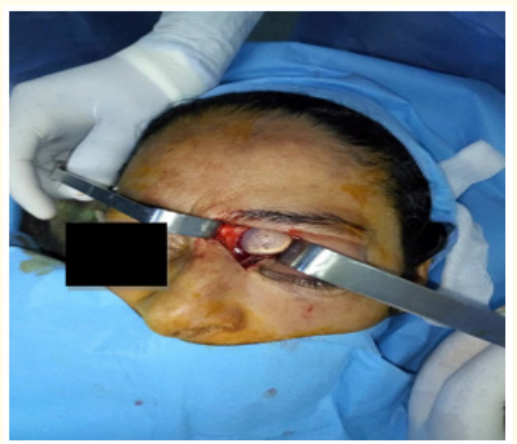

Figure 5: Per-operative image showing hydatic cyst delivery.

Histopathological examination confirmed the diagnosis of hydatic cyst. The surgical suites were simple with a regression of exophthalmia, good eye motility and a visual acuity not improveable on the fingers from afar with a papillary paleness at the back of the eye (Figure 6 and 7).

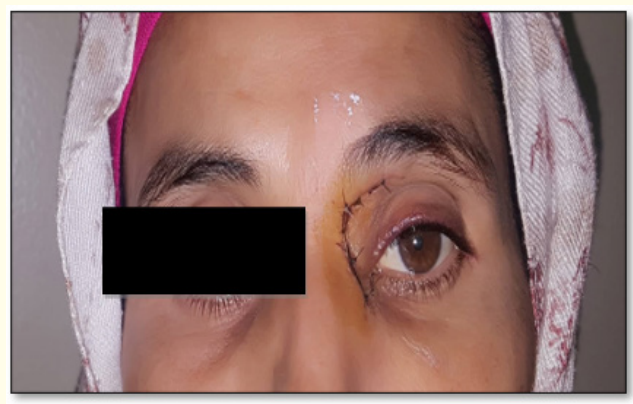

Figure 6: Post-operative image at J7. 


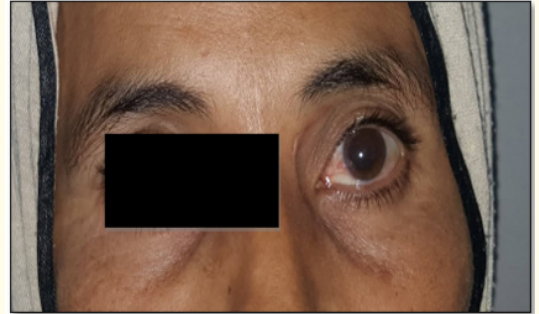

Figure 7: Image J45 of the post-operative: disappearance of exophthalmia.

\section{Discussion}

Ilbite anxiety is more common in young adults and children. Hydatidosis can involve almost all organs or tissues via portal and systemic circulations in humans. The mating is mainly liver $(60 \%$ to $70 \%$ ), pulmonary (20\%), followed by the central nervous system [1]. The orbit is a rare place of infestation by echinococs even in highly endemic areas and accounts for less than $1 \%$ of all damage $[3,5]$. Other systemic damage is rare in orbital hydatic cysts.

Orbital impairment is usually unlocular, with no right or left dominance [1,3]. Cysts are usually located in the retro bulb region and can be extraconic or, as in our case, intraconic. The preferred intra-orbital seat is mainly the super-internal seat (55\%) [3].

Unilateralexophthalmia is the most common clinical discovery in cases of intra-orbital [3] hydaticcysts. Any painless exophthalmia and progressive installation should make an orbital hydatic cyst strongly suspected in an endemic area. It is non-pulsatile, nonblowing, rarely axile, often painless and brutally installed. It can be accompanied by a loss of visual acuity, perorbital pain or palpebral edema.

The clinic is also marked by abnormalities in the back of the eye with a type of papillary perhhaemia, optic atrophy, creases and/ or retinal detachment [6]. Although serological tests are used to diagnose hydatic cyst, they are generally negative in case of orbital damage, as in our case. Imaging (ultrasound; CT scans)and magnetic resonance imaging (MRI) is essential to make the positive diagnosis, the final diagnosis will be confirmed by the histological examination, but it is worth noting the macroscopic aspect in peroperative which is very evocative.

Surgical removal is the treatment of choice for orbital hydatic cyst. It must be done with a wide path first and in a delicate way in order to prevent capsular eraction and the spread of parasitic disease [7].
Hydatic cyst is of good prognosis. The evolution is a function of the time taken care of and is generally done by the gradual disappearance of functional signs.

\section{Conclusion}

Intra-orbital hydatic location is rare and represents only 1 to $2 \%$ compared to other locations. It poses a differential diagnostic problem with other intra-orbital processes. Exophthalmia is at the forefront of symptomatology. Diagnosis is easy in front of a cluster of anamnestic, clinical and radiological arguments. The appropriate treatment for an orbital hydatic cyst is surgical removal.

\section{Bibliography}

1. Ergün R., et al. "Orbital hydatid cysts: Report of four cases". Neurosurgery Review 20.1 (1997): 33-37.

2. Turgut AT., et al. "Hydatidosis of the orbit in Turkey: results from review of the literature 1963-200". International Ophthalmology 25.4 (2004): 193-200.

3. Öztekin PS., et al. "Primary orbital hydatid cyst: computed tomography and magnetic resonance imaging findings". Singapore Medical Journal 55.11 (2014): e184-e186.

4. Gomez Morales A., et al. "Hydatid cysts of the orbit: a review of 35 cases”. Ophthalmology 95.8 (1988): 1027-1032.

5. Ciurea AV., et al. "Orbital hydatid cyst in childhood: a report of two cases". Southern Medical Journal 99 (2006): 6.

6. Kahveci R., et al. "Orbital hydatid cyst". Journal of Neurosurgery Pediatrics 9.1 (2012): 42-44.

7. Carrea R., et al. "Surgical treatment of hydatid cysts of the central nervous system in the pediatric age (Dowling's technique)". Childs Brain 1.1 (1975): 4-21.

\section{Assets from publication with us}

- Prompt Acknowledgement after receiving the article

- Thorough Double blinded peer review

- Rapid Publication

- Issue of Publication Certificate

- High visibility of your Published work

Website: www.actascientific.com/

Submit Article: www.actascientific.com/submission.php Email us: editor@actascientific.com Contact us: +919182824667 